\title{
Perda de matéria seca em grãos de milho armazenados em bolsas herméticas $^{1}$
}

\author{
Dry matter loss in corn grains stored in airtight bags
}

\author{
Silmara Bispo dos Santos ${ }^{2 *}$, Marcio Arêdes Martins ${ }^{3}$, Lêda Rita D’Antonino Faroni ${ }^{3}$ e Valfrido Rodrigues de \\ Brito Junior ${ }^{3}$
}

\begin{abstract}
RESUMO - O objetivo deste estudo foi avaliar a qualidade e a perda de matéria seca em grãos de milho armazenados em bolsas herméticas sob diferentes temperaturas. Para isso, grãos de milho com teor de água inicial de 14,8 e 17,9\% foram acondicionados em bolsas de polietileno lacradas e armazenados em temperaturas de $15 ; 25$ e $35^{\circ} \mathrm{C}$. Ao longo de 150 dias, em intervalos de 30 dias, as concentrações de oxigênio $\left(\mathrm{O}_{2}\right)$ e dióxido de carbono $\left(\mathrm{CO}_{2}\right)$ nas bolsas foram medidas e amostras dos grãos foram retiradas para a determinação do teor de água, massa específica aparente da matéria seca, percentual de germinação e classificação comercial. A perda de matéria seca foi estimada por meio de um modelo obtido como função da taxa respiratória dos grãos. Em 150 dias, a perda de matéria seca dos grãos de milho armazenados com teor de água de $14,8 \%$ foi aproximadamente 3,5 vezes inferior à verificada para o produto armazenado com teor de água de 17,9\%. Com base nos resultados de percentual de germinação e massa específica aparente da matéria seca, o limite de $0,015 \%$ de perda de matéria seca pode ser considerado como máximo admissível para a manutenção da integridade dos grãos no armazenamento em bolsas herméticas. Aos 150 dias, apenas, os grãos de milho armazenados com teor de água de $17,9 \%$ em temperatura de $35{ }^{\circ} \mathrm{C}$ apresentam classificação inferior (Tipo 2) à do início do experimento e esta condição coincidiu com a perda de matéria seca de $0,037 \%$.
\end{abstract}

Palavras-chave: Milho. Grãos-armazenamento. Taxa respiratória.

\begin{abstract}
The aim of this study was to evaluate the quality and loss of dry matter of corn grain stored in airtight bags at different temperatures. To do this, corn grain with an initial moisture content of 14.8 and $17.9 \%$ was placed into polyethylene bags which were sealed and stored at temperatures of 15,25 and $35^{\circ} \mathrm{C}$. For 150 days, at 30-day intervals, the concentrations of oxygen $\left(\mathrm{O}_{2}\right)$ and carbon dioxide $\left(\mathrm{CO}_{2}\right)$ in the bags were measured, and grain samples were taken to determine the moisture content, apparent specific dry matter weight, percentage of germination and commercial classification. Dry matter loss was estimated by means of a model obtained as a function of the respiratory rate of the grains. At 150 days, the loss of dry matter of the corn grains with a moisture content of $14.8 \%$ when stored, was approximately 3.5 times lower than that of the product with a moisture content of $17.9 \%$ when stored. Based on the results of the percentage of germination and apparent specific dry matter weight, the limit of a $0.015 \%$ loss in dry matter can be considered as the maximum permissible to maintain the integrity of corn grain in storage in sealed bags. At 150 days, only the corn grain, stored with moisture content of $17.9 \%$ and at a temperature of $35{ }^{\circ} \mathrm{C}$, showed a lower classification (Type 2) than at the beginning of the experiment, and this condition coincided with a dry matter loss of $0.037 \%$.
\end{abstract}

Key words: Maize. Grain-storage. Respiratory rate.

\footnotetext{
*Autor para correspondência

${ }^{1}$ Recebido para publicação em 12/02/2011; aprovado em 30/03/2012

Parte da Dissertação de Mestrado do primeiro autor, apresentada ao Programa de Pós-Graduação em Engenharia Agrícola/DEA/UFV

${ }^{2}$ Departamento de Engenharia Mecânica/FAG, Avenida das Torres, 500, Loteamento FAG, Cascavel-PR, Brasil, 85.806-095, syllmara@yahoo.com.br ${ }^{3}$ Departamento de Engenharia Agrícola, CCA/UFV, Avenida Peter Henry Rolfs s/n, Campus Universitário, Viçosa-MG, Brasil, 36.570-000, aredes@ufv.br, lfaroni@ufv.br, valfridobrito@hotmail.com
} 


\section{INTRODUÇÃO}

O milho, muito utilizado na alimentação animal e humana no Brasil e como matéria prima para o etanol norte americano tem se destacado no setor produtivo de grãos. O crescimento do cultivo desta cultura e de seu mercado consumidor demanda maiores cuidados, sobretudo na sua armazenagem.

$\mathrm{O}$ armazenamento em bolsas de polietileno, seladas hermeticamente, tem sido avaliado e utilizado para o armazenamento de soja, trigo e milho no Brasil e na Argentina como uma alternativa à grande demanda por unidades armazenadoras no campo (COSTA et al., 2010; FARONI et al., 2009; GASTÓN et al., 2009; SANTOS et al., 2010). Esta técnica resulta na redução da concentração de oxigênio $\left(\mathrm{O}_{2}\right)$ e acréscimo da concentração de dióxido de carbono $\left(\mathrm{CO}_{2}\right)$ devido ao processo respiratório dos componentes bióticos do ecossistema (grãos, fungos, insetos, etc.) (EMEKCI et al., 2002; EMEKCI et al., 2004, NAVARRO; DONAHAYE, 2005). A atmosfera rica em $\mathrm{CO}_{2}$ e pobre em $\mathrm{O}_{2}$ pode reduzir a capacidade de reprodução e/ou desenvolvimento de insetos, de fungos, como também a própria atividade metabólica dos grãos, favorecendo a sua conservação (AGUIAR et al., 2004; QUEZADA et al., 2006). Soma-se a isso, a redução da taxa respiratória e conseqüentemente a redução das perdas por oxidação do produto (VILLERS; BRUIN; NAVARRO, 2006).

A taxa respiratória tem sido utilizada por diversos autores para estimar a perda de matéria seca dos grãos durante o armazenamento (ALVES et al., 2006; BERN;STEELE;MOREY, 2002; DILLAHUNTY et al., 2000; ILELEJI et al., 2003; SAUL;STEELE, 1966). Nestes estudos, a taxa respiratória foi expressa como a razão entre a massa de gás carbônico $\left(\mathrm{CO}_{2}\right)$ produzida e a massa de matéria seca dos grãos. Nos modelos propostos, a produção de $\mathrm{CO}_{2}$ foi convertida em perda de matéria seca dos grãos considerando o processo de respiração aeróbica com a completa oxidação dos carboidratos em $\mathrm{CO}_{2}$, água $\left(\mathrm{H}_{2} \mathrm{O}\right)$ e calor. Neste contexto, a produção de $14,7 \mathrm{~g}$ de $\mathrm{CO}_{2}$ por kg de matéria seca dos grãos equivale a $1 \%$ de perda de matéria seca (SAUL; STEELE, 1966).

De acordo com Saul e Steele (1966), Gupta et al. (1998) e Dillahunty et al. (2000), os fatores: teor de água dos grãos, índice de danos mecânicos, temperatura dos grãos e do ambiente de armazenamento e a composição da atmosfera, sobretudo a disponibilidade de $\mathrm{O}_{2}$, influenciam a atividade respiratória dos grãos e consequiente a perda de matéria seca.

Saul e Steele (1966) verificaram que independente da temperatura, teor de água e danos mecânicos, de acordo com a classificação comercial norte americana, o milho passa de tipo 2 para tipo 3 quando a perda de matéria seca atinge o nível de 0,5\%. Após este estudo, muitos pesquisadores passaram a utilizar o valor de $0,5 \%$ como o máximo permissível de perda de matéria seca em modelos de simulações para secagem e armazenamento de milho.

O efeito da composição da atmosfera não foi objeto de estudo destes autores na avaliação da taxa respiratória e da perda de matéria seca de grãos, uma vez que o armazenamento foi conduzido em sistemas abertos.

A perda de matéria seca em sistema hermético foi estudada por Adhikarinayake et al. (2006) durante o armazenamento de arroz com casca, no entanto, o estudo foi realizado em uma única condição de temperatura e teor de água inicial.

Diante do exposto, objetivou-se com o presente trabalho estimar a perda de matéria seca dos grãos de milho armazenados em bolsas herméticas sob diferentes condições de temperatura e identificar as possíveis relações desta perda com a qualidade final do produto.

\section{MATERIAL E MÉTODOS}

O trabalho foi desenvolvido no Laboratório de PréProcessamento e Armazenamento de Produtos Agrícolas do Departamento de Engenharia Agrícola da Universidade Federal de Viçosa. Foram utilizados grãos de milho (Zea mays L.) do grupo semi-duro, classe amarelo e classificado inicialmente como Tipo 1, colhidos manualmente em propriedade rural localizada na região de Viçosa - MG. Dois lotes de grãos inicialmente com teores de água de 23 e $18 \%$ foram secos em secador de leito fixo com ar natural até os teores de água médio de 17,9 e 14,8\%, respectivamente.

Os grãos foram distribuídos em bolsas de polietileno de alta densidade e impermeável a gases como $\mathrm{CO}_{2}, \mathrm{O}_{2}$ e $\mathrm{N}_{2}$ (nitrogênio), confeccionadas com o mesmo material utilizado em silos bolsa comercial, porém, com capacidade para $2 \mathrm{~kg}$ de grãos. As bolsas foram lacradas e armazenadas em câmara sob temperaturas controladas de $15 ; 25$ e $35^{\circ} \mathrm{C}$. Foram utilizadas no total 90 bolsas, sendo três bolsas (repetições) para cada teor de água inicial dos grãos $(14,8$ e $17,9 \%)$, temperatura $\left(15 ; 25\right.$ e $\left.35^{\circ} \mathrm{C}\right)$ e período de armazenamento $(0 ; 30 ; 60 ; 90 ; 120$ e 150 dias $)$.

Ao longo de 150 dias, em intervalos de 30 dias, três bolsas correspondentes a cada teor de água e temperatura foram retiradas das câmaras para a medição das concentrações de $\mathrm{O}_{2} \mathrm{e} \mathrm{CO}_{2}$, e os grãos foram submetidos às análises de teor de água, massa específica aparente da matéria seca, percentual de germinação e classificação comercial.

$\mathrm{O}$ teor de água foi determinado por meio do método de estufa a $105 \pm 3{ }^{\circ} \mathrm{C}$, de acordo com as Regras para Análise de Sementes (BRASIL, 2009). 
A massa específica aparente da matéria seca $\rho_{\mathrm{ms}}$ $\left(\mathrm{kgm}^{-3}\right)$ dos grãos foi determinada como:

$\rho_{\mathrm{ms}}=\rho_{\mathrm{g}}\left(1-\frac{\mathrm{Mc}}{100}\right)$

Em que $\rho_{\mathrm{g}}$ é a massa específica aparente dos grãos de milho $\left(\mathrm{kg} \mathrm{m}^{-3}\right)$ e Mc é o teor de água dos grãos (\% b.u.).

A massa específica aparente dos grãos foi determinada em três repetições, por meio de uma balança de peso hectolítrico com capacidade para $250 \mathrm{ml}$.

O percentual de germinação foi avaliado de acordo com as Regras para Análise de Sementes (BRASIL, 2009), utilizando-se 200 grãos de milho distribuídos em quatro repetições de 50 grãos, com avaliação ao sétimo dia.

Os grãos de milho foram classificados de acordo com a Portaria No 845, de 08.11.1976, do Ministério da Agricultura, publicada no D.O.U. de 19.11.1976 (BRASIL, 1976).

A concentração de $\mathrm{CO}_{2}$ na atmosfera intergranular foi determinada por volumetria. Alíquotas de $25 \mathrm{~mL}$ de gás foram retiradas das bolsas e adicionadas em frascos herméticos contendo $2 \mathrm{~mL}$ de solução de $\mathrm{NaOH}(0,1)$. $\mathrm{O}$ teor de carbonatos e bicarbonatos produzidos foi determinado conforme (VOGEL, 2002) e relacionado com a concentração de $\mathrm{CO}_{2}$ na amostra de gás. A concentração de $\mathrm{O}_{2}$ foi determinada utilizando-se um analisador de gases da marca TESTO, modelo 330.1.

O modelo proposto para a estimativa da perda de matéria seca foi desenvolvido considerando-se os processos simultâneos de respiração aeróbica e anaeróbica, que ocorrem em baixas concentrações de $\mathrm{O}_{2}$, característica do processo de armazenamento hermético. Foi considerado que a perda de matéria seca devido à respiração ocorre pela decomposição da glicose segundo dois mecanismos distintos. Durante o processo de respiração aeróbica, ocorre a decomposição dos carboidratos em $\mathrm{CO}_{2}$ e $\mathrm{H}_{2} \mathrm{O}$ e durante o processo de respiração anaeróbica ocorre a decomposição dos carboidratos em $\mathrm{CO}_{2}$ e etanol $\left(\mathrm{C}_{2} \mathrm{H}_{5} \mathrm{OH}\right)$. Os processos de respiração aeróbica e anaeróbica podem ser descritos pelas equações 2 e 3 :

$\mathrm{x} \mathrm{C}_{6} \mathrm{H}_{12} \mathrm{O}_{6}+6 \mathrm{x} \mathrm{O}_{2} \rightarrow 6 \mathrm{x} \mathrm{O}_{2} 6 \mathrm{x} \mathrm{H}_{2} \mathrm{O}+\mathrm{x} 677 \mathrm{cal}$

$\mathrm{y} \mathrm{C}_{6} \mathrm{H}_{12} \mathrm{O}_{6} \rightarrow 2 \mathrm{y} \mathrm{C}_{2} \mathrm{H}_{5} \mathrm{OH}+2 \mathrm{y} \mathrm{CO}_{2}+\mathrm{y} 22 \mathrm{cal}$

Emque, $\mathrm{x}$ e y sãoas quantidades molares de glicoseconsumidas de acordo com as equações 2 e 3 , respectivamente.

Para a determinação da perda de matéria seca ao longo do armazenamento estas quantidades molares foram determinadas por meio das concentrações de $\mathrm{CO}_{2}$ produzido e de $\mathrm{O}_{2}$ consumido dentro das bolsas herméticas ao longo do período de armazenamento. O modelo final para a estimativa da perda de matéria seca considerando a ocorrência de processos simultâneos de respiração aeróbica e anaeróbica em sistema hermético pode ser representado pela equação 4 :

$\mathrm{P}_{\mathrm{ms}}=100\left(\mathrm{C}_{\mathrm{CO}_{2}}-\Delta \mathrm{C}_{\mathrm{O}_{2}}\right)\left(\frac{\varepsilon \mathrm{PW}_{\mathrm{g}}}{2 \rho_{\mathrm{g}}(1-\mathrm{Mcd}) \mathrm{R} \mathrm{T}}\right)$

Em que, $\Delta \mathrm{C}_{02}$ é a variação da concentração de $\mathrm{O}_{2}$ ao longo do armazenamento hermético considerando a concentração inicial de $21 \%$; $\mathrm{C}_{02}$ é a concentração de $\mathrm{CO}_{2}$ (v/v) medida nas bolsas herméticas; $\varepsilon$ é a porosidade da massa granular; $P$ é a pressão atmosférica local $(96 \mathrm{kPa}) ; \mathrm{W}_{\mathrm{g}}$ é a massa molar da glicose $\left(180 \mathrm{~kg} \mathrm{kmol}^{-1}\right) ; \rho_{\mathrm{g}}$ é a massa específica aparente dos grãos $\left(\mathrm{kg} \mathrm{m}^{-3}\right)$; Mcd é o teor de água dos grãos (decimal b.u.); $R$ é a constante dos gases perfeitos $\left(8,314 \mathrm{~kJ} \mathrm{kmol}^{-1} \mathrm{~K}^{-1}\right)$; e $T$ é a temperatura $(\mathrm{K})$.

Utilizou-seodelineamentoexperimentalinteiramente casualizado em esquema fatorial $2 \times 3 \times 6$, sendo 2 teores de água $(14,8$ e $17,9 \%), 3$ temperaturas $\left(15 ; 25\right.$ e $\left.35^{\circ} \mathrm{C}\right) \mathrm{e}$ seis períodos de tempo $(0 ; 30 ; 60 ; 90 ; 120$ e 150 dias $)$. O software SPSS para Windows foi utilizado para a análise dos resultados. A análise de variância foi utilizada para avaliar o efeito dos fatores bem como da interação entre eles, sobre os parâmetros avaliados. A análise de regressão foi realizada para avaliar a dependência das variáveis, massa específica aparente da matéria seca e perda de matéria seca com relação ao tempo de armazenamento.

\section{RESULTADOS E DISCUSSÃO}

O teor de água dos grãos de milho foi determinado ao longo do armazenamento hermético em diferentes temperaturas e os valores médios obtidos estão apresentados na Tabela 1 e Figura 1. Com relação ao teor de água médio, não houve diferença significativa entre as temperaturas de 15; 25 e $35^{\circ} \mathrm{C}$, independentemente do teor de água inicial dos grãos. A variação observada ao longo do tempo de armazenamento também não foi significativa de acordo com a análise de regressão (Figura 1). Este resultado era esperado, uma vez que em sistemas herméticos não ocorrem trocas com o ambiente externo. Apesar do processo de respiração dos grãos e microorganismos presentes produzir água $\left(\mathrm{H}_{2} \mathrm{O}\right)$ enquanto consome o $\mathrm{O}_{2}$, a massa de água produzida é pequena para causar uma variação significativa no teor de água do produto.

De acordo com os resultados da análise de variância (Tabela 2), todos os fatores avaliados (teor de água dos grãos, temperatura e tempo de armazenamento) e todas as interações entre eles, influenciaram de forma significativa ( $P>0,05)$ o percentual de germinação, a massa específica aparente da matéria seca e a perda de matéria seca dos grãos de milho armazenados em bolsas herméticas.

$\mathrm{O}$ potencial de germinação dos grãos de milho armazenados com teor de água de 14,8\% nas temperaturas 
Tabela 1 - Valores médios de teor de água dos grãos de milho armazenados hermeticamente com teores de água inicial de 14,8 e $17,9 \%$ em diferentes temperaturas

\begin{tabular}{ccccccc}
\hline \multirow{2}{*}{ Temperatura $\left({ }^{\circ} \mathrm{C}\right)$} & \multicolumn{7}{c}{ Tempo (dias) } \\
\cline { 2 - 7 } & 0 & 30 & 60 & 90 & 120 & 150 \\
\hline 15 & $14,8 \pm 0,10 \mathrm{a}$ & $14,7 \pm 0,14 \mathrm{a}$ & $14,9 \pm 0,03 \mathrm{a}$ & $15,1 \pm 0,24 \mathrm{a}$ & $15,2 \pm 0,11 \mathrm{a}$ & $14,9 \pm 0,37 \mathrm{a}$ \\
25 & $14,8 \pm 0,10 \mathrm{a}$ & $14,5 \pm 0,07 \mathrm{a}$ & $14,7 \pm 0,15 \mathrm{a}$ & $15,1 \pm 0,22 \mathrm{a}$ & $15,3 \pm 0,05 \mathrm{a}$ & $14,7 \pm 0,09 \mathrm{a}$ \\
35 & $14,8 \pm 0,10 \mathrm{a}$ & $14,7 \pm 0,16 \mathrm{a}$ & $14,7 \pm 0,11 \mathrm{a}$ & $15,0 \pm 0,04 \mathrm{a}$ & $15,0 \pm 0,15 \mathrm{a}$ & $14,9 \pm 0,06 \mathrm{a}$ \\
15 & $17,9 \pm 0,20 \mathrm{a}$ & $17,9 \pm 0,45 \mathrm{a}$ & $17,8 \pm 0,37 \mathrm{a}$ & $18,2 \pm 0,60 \mathrm{a}$ & $17,9 \pm 0,70 \mathrm{a}$ & $17,5 \pm 0,15 \mathrm{a}$ \\
25 & $17,9 \pm 0,20 \mathrm{a}$ & $17,5 \pm 0,01 \mathrm{a}$ & $17,7 \pm 0,14 \mathrm{a}$ & $17,6 \pm 0,10 \mathrm{a}$ & $18,1 \pm 0,08 \mathrm{a}$ & $17,1 \pm 0,12 \mathrm{a}$ \\
35 & $17,9 \pm 0,20 \mathrm{a}$ & $17,4 \pm 0,09 \mathrm{a}$ & $17,4 \pm 0,02 \mathrm{a}$ & $17,5 \pm 0,16 \mathrm{a}$ & $17,7 \pm 0,17 \mathrm{a}$ & $17,4 \pm 0,17 \mathrm{a}$ \\
\hline
\end{tabular}

Médias seguidas da mesma letra na mesma coluna para cada teor de água inicial, não diferem entre si pelo teste de Tukey $(\mathrm{P}>0,05)$

Figura 1 - Teor de água de grãos de milho com teores de água de $14,8 \%$ (A) e $17,9 \%$ (B) ao longo do armazenamento hermético em diferentes temperaturas

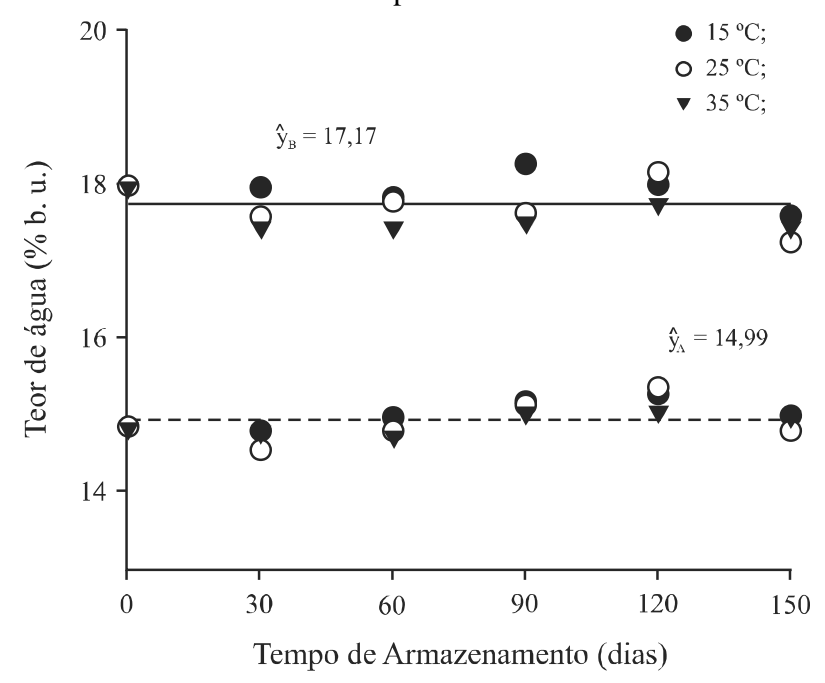

de 15 e $25^{\circ} \mathrm{C}$ e com teor de água de $17,9 \%$ em temperatura de $15{ }^{\circ} \mathrm{C}$ mantiveram-se praticamente constante, durante os 150 dias de armazenamento. Para as demais condições houve redução significativa destes valores com o tempo de armazenamento (Figura 2). Para os grãos armazenados com $17,9 \%$, observa-se que quanto maior a temperatura maior as taxas de redução (Figura 2B).

Para os grãos de milho armazenados com teor de água de $14,8 \%$ em temperatura de $35{ }^{\circ} \mathrm{C}$, a relação de dependência entre o percentual de germinação e o tempo de armazenamento pode ser representada pelo modelo:

$\hat{y}=94,63 * * /(1+\exp ((x-76,70 * *) / 12,39 * *)), \operatorname{com~R}^{2}=0,99$ (** parâmetros significativos a $1 \%$ ).

Para os grãos de milho armazenados com teor de água de $17,9 \%$ em temperatura de $25^{\circ} \mathrm{C}$ esta relação pode ser representada por:

$\hat{\mathrm{y}}=100,55^{* *} /\left(1+\exp \left(\left(\mathrm{x}-65,22^{* *}\right) / 16,86^{*}\right)\right), \operatorname{com} \mathrm{R}^{2}=0,99$

Tabela 2 - Resumo da análise de variância das variáveis: percentual de germinação (PG) massa específica aparente da matéria seca (MEMS), e perda de matéria seca (PMS) dos grãos de milho com teores de água de 14,8 e 17,9\% b.u., armazenados em bolsas herméticas

\begin{tabular}{lcccc}
\hline \multirow{2}{*}{ Fonte de variação } & G.L. & \multicolumn{3}{c}{ Quadrados médios } \\
\cline { 3 - 5 } & 1 & $21737,37^{* *}$ & MEMS & PMS \\
\hline Teor de água (TA) & 2 & $33142,94^{* *}$ & $4760,69 * *$ & $72,98^{* *}$ \\
Temperatura (T) & 5 & $7348,47^{* *}$ & $672,95^{* *}$ & $6,48^{* *}$ \\
Período de armazenamento (P) & 2 & $4491,76^{* *}$ & $56,01^{* *}$ & $7,42^{* *}$ \\
TAxT & 5 & $952,71^{* *}$ & $28,69^{*}$ & $4,53^{* *}$ \\
TAxP & 10 & $2047,31^{* *}$ & $57,34^{* *}$ & $3,98^{* *}$ \\
TxP & 10 & $2017,15^{* *}$ & $20,71 *$ & $0,56^{* *}$ \\
TAxTxP & 72 & 19,51 & 9,66 & $0,45^{* *}$ \\
Resíduo & & 6,85 & 0,516 & 0,0001 \\
CV $(\%)$ & & & 0,952 \\
\hline
\end{tabular}

*, ** Significativo a 5 e $1 \%$, respectivamente, pelo teste $\mathrm{F}$ 
Figura 2 - Percentual de germinação dos grãos de milho com teores de água de 14,8\% (A) e 17,9\% (B) ao longo do armazenamento hermético em diferentes temperaturas

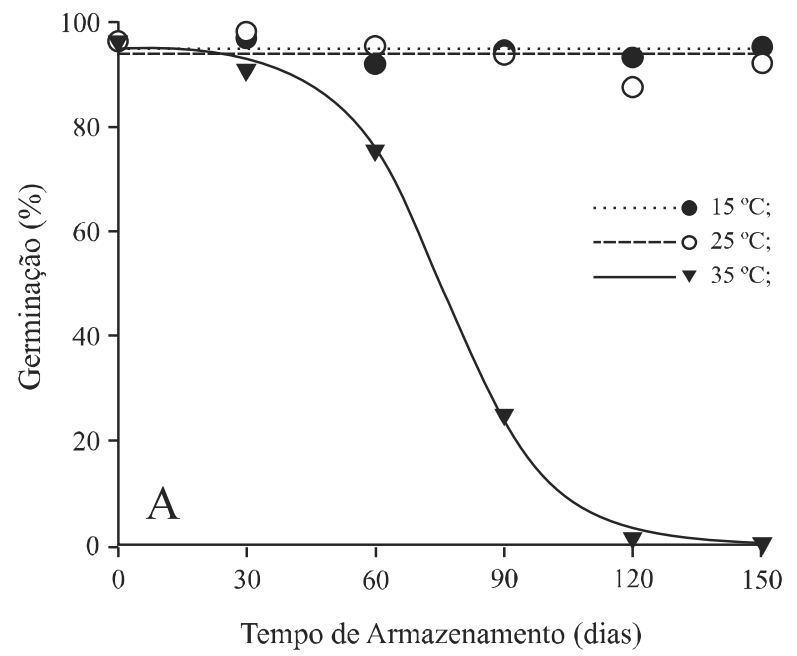

(*; ** Parâmetros significativos a 5 e $1 \%$, respectivamente).

Resultados semelhantes foram reportados por Weinberg et al. (2008) e Costa et al. (2010), durante o armazenamento de milho em sistema hermético. Ambos os autores observaram maior perda do percentual de germinação em grãos armazenados com elevados teores de água quando comparado aos grãos armazenados secos. Costa et al. (2010), reporta também que as taxas em que ocorrem estas perdas dependem não apenas do teor de água, mas também da temperatura. Estes autores verificaram que em temperatura de $35{ }^{\circ} \mathrm{C}$, mesmo armazenando grãos de milho em bolsas herméticas com baixo teor de água (14,3\% b.u.), aos 135 dias o produto havia perdido $100 \%$ do seu poder germinativo.

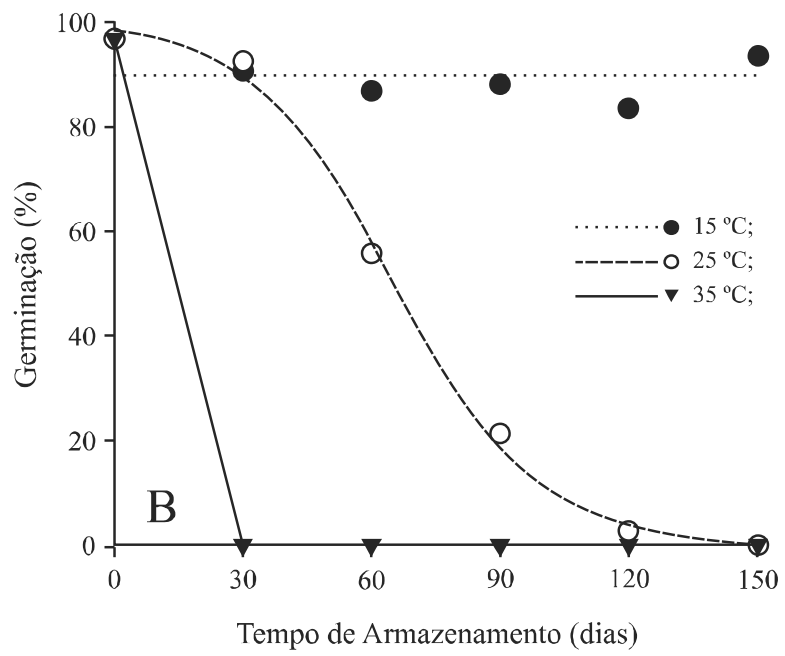

Rupollo et al. (2004) e Quezada et al. (2006) também verificaram uma tendência para a redução do potencial germinativo dos grãos de aveia com teor de água inicial de $11 \%$ e milho com teor de água inicial de $17 \%$, respectivamente, durante o armazenamento hermético. De acordo com Moreno, Beravides e Ramires (1988), sementes de milho mantêm sua viabilidade por períodos relativamente curtos quando armazenadas em condições herméticas, a menos que estas sejam armazenadas com teor de água abaixo de 14\%, ou em temperaturas semelhantes às utilizadas em bancos de germoplasma $\left(-20\right.$ a $\left.1^{\circ} \mathrm{C}\right)$.

Os valores das concentrações de $\mathrm{O}_{2}$ e $\mathrm{CO}_{2}$ ao longo do armazenamento dos grãos de milho em diferentes temperaturas

Figura 3 - Concentração de $\mathrm{CO}_{2}$ e $\mathrm{O}_{2}$ observadas e estimadas nas bolsas contendo grãos de milho com teores de água de 14,8\% (A) e $17,9 \%$ (B) ao longo do armazenamento hermético em diferentes temperaturas
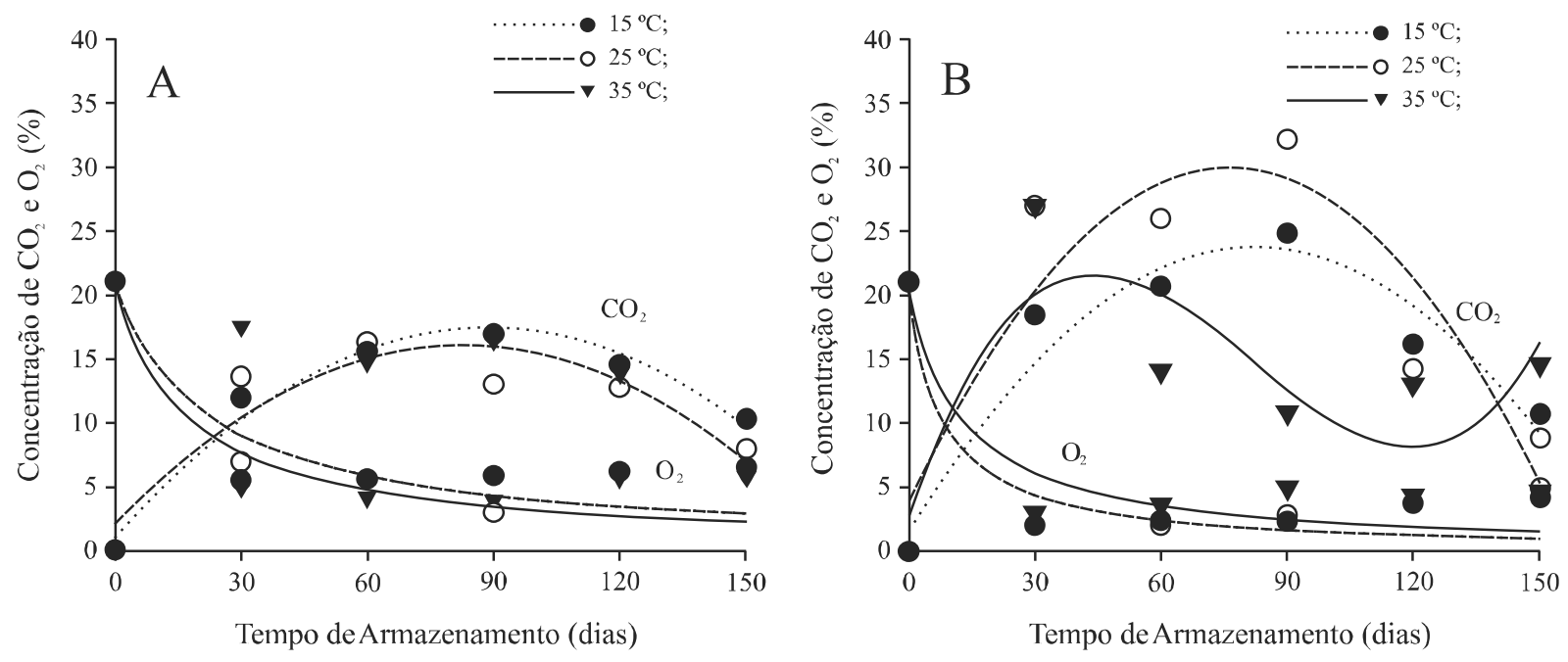
estão representados na Figura 3. Os modelos ajustados aos dados experimentais estão apresentados na Tabela 3.

Como esperado para sistema hermético, observa-se que ocorreu elevação das concentrações de $\mathrm{CO}_{2}$ e redução das concentrações de $\mathrm{O}_{2}$ no interior das bolsas, independentemente da temperatura. A relação de dependência da concentração de $\mathrm{O}_{2}$ com o tempo de armazenamento pode ser representada por modelos racionais de dois parâmetros (Tabela 3). Para todas as condições avaliadas, as maiores taxas de decréscimo ocorreram no período inicial de 30 dias de armazenamento. Após este período as concentrações de $\mathrm{O}_{2}$ mantiveram-se praticamente constantes em torno das médias 5,37 e 3,36\% para as bolsas contendo grãos de milho com teores de água de 14,8 e 17,9\%, respectivamente. Estes valores correspondem à média das concentrações das 3 temperaturas após 30 dias de armazenamento.

Apesar das concentrações de $\mathrm{O}_{2}$ manterem-se praticamente constantes após 30 dias, as concentrações de $\mathrm{CO}_{2}$ aumentaram até atingir valores máximos, o que indica que a partir de 30 dias de armazenamento os grãos de milho passaram a realizar suas atividades respiratórias por via anaeróbica, ou seja, produzindo $\mathrm{CO}_{2}$ mesmo sem o consumo de $\mathrm{O}_{2}$.

A diminuição da concentração de $\mathrm{O}_{2}$ em um sistema hermético depende, em grande parte, de vários elementos que compõem o sistema de armazenamento como a população de insetos e fungos, teor de água ou atividade de água, qualidade do grão e volume de $\mathrm{O}_{2}$ disponível inicialmente (QUEZADA et al., 2006).

Derivando as equações (Tabela 3) que representam a relação de dependência das concentrações de $\mathrm{CO}_{2}$ com o tempo de armazenamento obteve-se o tempo estimado para a obtenção de máximas concentrações de $\mathrm{CO}_{2}$ nas diferentes condições de armazenamento. Para as bolsas contendo milho armazenado com teor de água de $14,8 \%$ os valores máximos estimados foram 17,11\% em 92 dias, 13,76\% em 81 dias e $15,04 \%$ em 79 dias, para as temperaturas de $15 ; 25$ e $35^{\circ} \mathrm{C}$, respectivamente (Figura 3A). Para as bolsas contendo milho armazenado com teor de água de $17,9 \%$ os valores máximos estimados foram $21,94 \%$ em 83 dias, 26,44\% em 77 dias e 16,33\% em 33 dias, para as temperaturas de $15 ; 25$ e $35{ }^{\circ} \mathrm{C}$, respectivamente (Figura 3B). Diferentemente do que se esperava, para os grãos armazenados com teor de água de 17,9\%, a maior produção de $\mathrm{CO}_{2}$ pelos grãos não ocorreu em temperatura de $35^{\circ} \mathrm{C}$, mas em temperatura de $25^{\circ} \mathrm{C}$. Uma possível explicação para este resultado é que na temperatura de $35^{\circ} \mathrm{C}$, aos 30 dias de armazenamento, os grãos armazenados com este teor de água não apresentaram mais qualquer potencial de germinação, não sendo capazes de produzir $\mathrm{CO}_{2}$ por ter sua atividade respiratória comprometida. Alves et al. (2006) também verificaram que em temperatura de $25^{\circ} \mathrm{C}$ a taxa respiratória dos grãos de milho expressas em mg de $\mathrm{CO}_{2}$ por $\mathrm{kg}$ de matéria seca é maior quando comparada às temperaturas de $30 ; 35$ e $40{ }^{\circ} \mathrm{C}$.

$\mathrm{O}$ excesso de ar contido nas bolsas foi retirado no momento do seu fechamento, permitindo que as concentrações de $\mathrm{CO}_{2}$ para os grãos de milho armazenados com teor de água inicial de 14,8 e 17,9\% fossem baixas quando comparadas às verificadas por Wheinberg et al. (2008). Estes autores armazenaram grãos de milho com diferentes teores de água em recipientes de vidro herméticos, sob temperatura de $30{ }^{\circ} \mathrm{C}$, e mediram as concentrações de $\mathrm{CO}_{2}, \mathrm{O}_{2}$ e $\mathrm{N}_{2}$ ao longo de 75 dias. Para grãos armazenados com teor de água de 14; 16 e 18\% obtiveram concentrações máximas da ordem de $15 ; 42$ e $74 \%$, respectivamente. No entanto, os recipientes utilizados por eles, não foram completamente preenchidos de grãos. $\mathrm{O}$ ar em excesso e uma maior quantidade de $\mathrm{O}_{2}$ disponível possivelmente permitiu que os grãos e a microflora presente realizassem suas atividades respiratórias por via aeróbica, produzindo maiores quantidades de $\mathrm{CO}_{2}$.

Tabela 3 - Modelos de regressão ajustados para as concentrações de $\mathrm{O}_{2}$ e $\mathrm{CO}_{2}$ medidas nas bolsas contendo grãos de milho com teores de água de 14,8 e 17,9\% (b.u.) ao longo do armazenamento hermético em diferentes temperaturas

\begin{tabular}{|c|c|c|c|}
\hline \multirow{2}{*}{$\begin{array}{c}\text { Teor de água } \\
(\%)\end{array}$} & \multirow{2}{*}{ Temperatura $\left({ }^{\circ} \mathrm{C}\right)$} & \multicolumn{2}{|c|}{ Modelos de regressão } \\
\hline & & $\mathrm{O}_{2}(\%)$ & $\mathrm{CO}_{2}(\%)$ \\
\hline \multirow{3}{*}{14,8} & 15 & $\hat{y}=1 /(0,049+0,002 x) R^{2}=0,77$ & $\hat{y}=0,94^{\mathrm{ns}}+0,37 \mathrm{x}-0,002 \mathrm{x}^{2} \mathrm{R}^{2}=0,95$ \\
\hline & 25 & $\hat{y}=1 /(0,048+0,0021 x) R^{2}=0,83$ & $\hat{y}=1,97^{n s}+0,34 x-0,0021 x^{2} R^{2}=0,73$ \\
\hline & 35 & $\hat{y}=1 /(0,049+0,0028 x) R^{2}=0,83$ & $\hat{y}=2,50^{\mathrm{ns}}+0,38 x-0,0024 x^{2} \quad R^{2}=0,68$ \\
\hline \multirow{3}{*}{17,9} & 15 & $\hat{y}=1 /(0,048+0,0066 x) R^{2}=0,90$ & $\hat{y}=1,77^{\text {ns }}+0,53 x-0,003 x^{2} \quad R^{2}=0,86$ \\
\hline & 25 & $\hat{y}=1 /(0,048+0,006 x) R^{2}=0,88$ & $\hat{y}=3,47^{n s}+0,69 x-0,0045 x^{2} \quad R^{2}=0,70$ \\
\hline & 35 & $\hat{y}=1 /(0,048+0,0038 x) \quad R^{2}=0,83$ & $\hat{y}=2,18^{n s}+0,99 x-0,015 x^{2}+0,00006^{n s} x^{3} \quad R^{2}=0,67$ \\
\hline
\end{tabular}

${ }^{\text {ns }}$ Parâmetros não significativos a $5 \%$ pelo teste $\mathrm{F}$ 
A redução nas concentrações intergranulares de $\mathrm{CO}_{2}$ verificadas neste trabalho pode estar associada à ocorrência de sorção de $\mathrm{CO}_{2}$ pelos grãos. As bolsas contendo os grãos se apresentaram rígidas e compactadas, com uma pressão interna menor que a pressão do ambiente $(94,26 \mathrm{kPa})$. A compactação verificada nas bolsas descarta qualquer possibilidade de vazamentos e reforça a hipótese da existência do processo de sorção. Wheinberg et al. (2008) mediram a concentração de gases existentes ao longo do armazenamento de grãos de milho em ambiente hermético, sob temperatura de $30^{\circ} \mathrm{C}$. Nestes estudos, aqueles autores não verificaram redução nas concentrações de $\mathrm{CO}_{2}$, no entanto, foi utilizado um período de armazenamento inferior (75 dias). Shunmugam et al. (2005) verificaram que quantidades significativas de $\mathrm{CO}_{2}$ são sorvidas por grãos de trigo, canola e cevada, e que esta sorção de $\mathrm{CO}_{2}$ é influenciada pela temperatura e pelo teor de água dos grãos.

A relação de dependência da variável massa específica aparente com o tempo pode ser representada adequadamente por modelos lineares apresentados na Figura 4.

Houve um decréscimo da massa específica aparente da matéria seca dos grãos de milho armazenados em bolsas herméticas com o aumento do tempo para todas as temperaturas (Figura 4).

Os coeficientes angulares, ou seja, a inclinação das retas obtidas na análise de regressão são as taxas de redução da massa específica aparente da matéria seca. Observase que as maiores taxas de redução ocorreram nos grãos armazenados com teor de água de 17,9\% armazenados em temperaturas de 25 e $35^{\circ} \mathrm{C}$. A redução da massa específica da matéria seca em grãos geralmente está associada a um aumento de volume devido a ganho de água, ou à perda de matéria seca. Como o teor de água dos grãos se manteve constante ao longo do armazenamento, acredita-se que as reduções verificadas estão relacionadas exclusivamente à perda de matéria seca. De fato, estes resultados estão de acordo com os resultados obtidos para a perda de matéria seca estimada pela taxa respiratória dos grãos (Figura 5).

A máxima perda de matéria seca dos grãos de milho armazenados com teor de água de $14,8 \%$ foi estimada em 0,0124; 0,014 e 0,015\% (Figura 5A) e para os grãos armazenados com teor de água de 17,9\% foi estimada em, 0,037; 0,052 e 0,037\% (Figura 5B) para as temperaturas de $15 ; 25$ e $35^{\circ} \mathrm{C}$, respectivamente.

Em geral, as maiores taxas de perda de matéria seca dos grãos armazenados em bolsas herméticas ocorreram nos períodos iniciais. A partir de 30 dias, quando os grãos já estavam em fase de anaerobiose, à medida que se aumenta o tempo de armazenamento, estas taxas decresceram e tenderam a zero (Figura 5). Nesta etapa, os grãos e microorganismos presentes continuam suas atividades respiratórias, porém, a produção de $\mathrm{CO}_{2}$ passa a ser menor do que na fase aeróbica, explicando o decréscimo das taxas de perda de matéria seca.

A maior perda de matéria seca ocorreu para os grãos com teor de água de 17,9\% em temperatura de $25{ }^{\circ} \mathrm{C}(0,052 \%)$ (Figura 5$)$, pois com a elevação da temperatura ocorre um aumento da atividade respiratória dos grãos e dos organismos vivos que compõem o sistema, ocasionando maior produção de $\mathrm{CO}_{2}$ e, consequientemente, maior perda de matéria seca. A total mortalidade dos grãos armazenados com teor de água de $17,9 \% \mathrm{em}$ temperatura de $35{ }^{\circ} \mathrm{C}$ comprometeu a produção de $\mathrm{CO}_{2}$.

Figura 4 - Massa específica aparente da matéria seca de grãos de milho com teores de água de 14,8\% (A) e 17,9\% (B) ao longo do armazenamento hermético em diferentes temperaturas
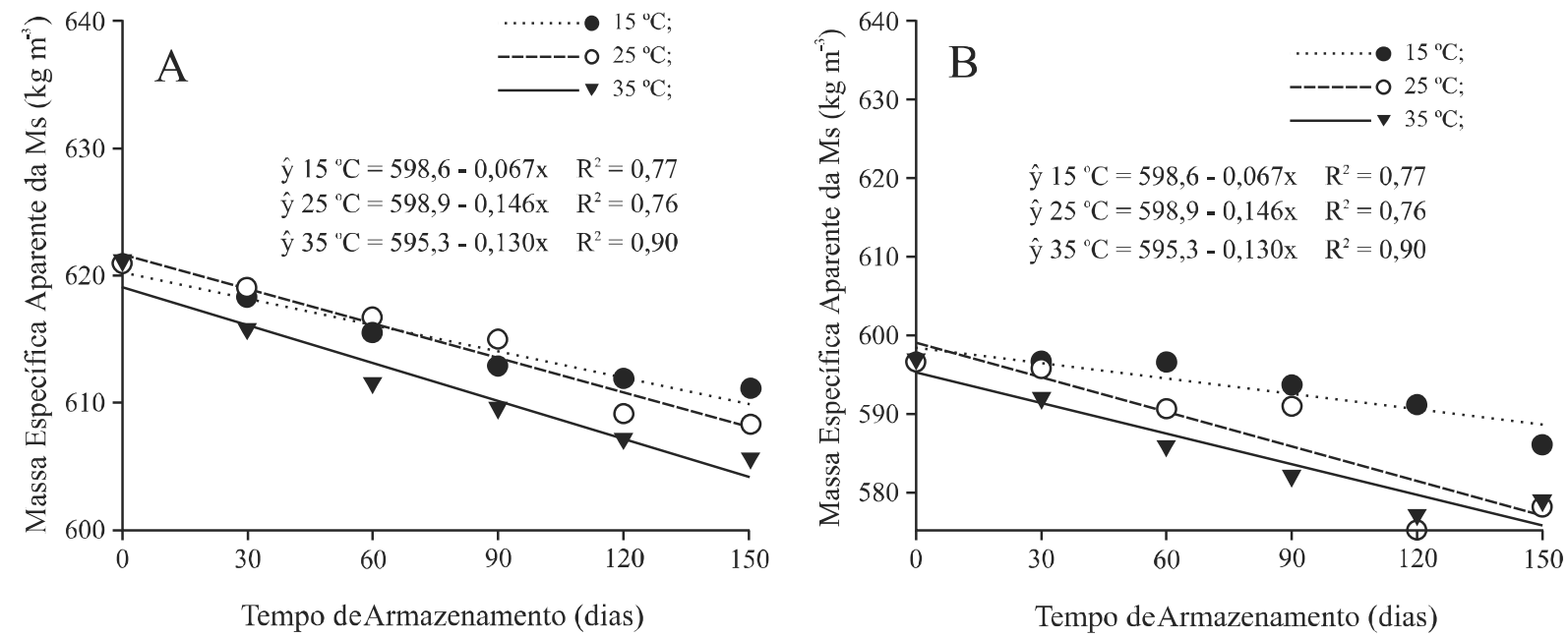
Figura 5 - Perda de matéria seca de grãos de milho com teores de água de 14,8\% (A) e 17,9\% (B) ao longo do armazenamento hermético em diferentes temperaturas

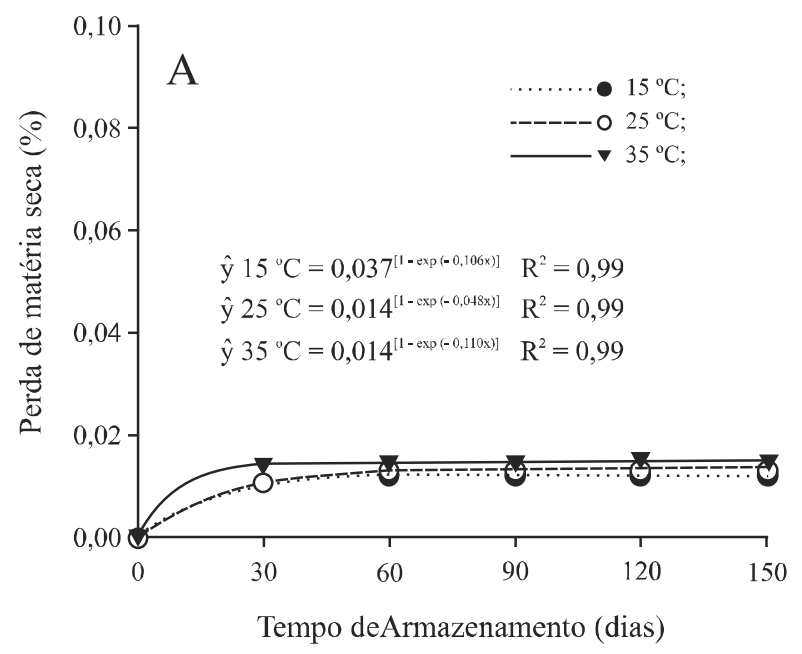

Este fato justifica uma menor perda de matéria seca dos grãos estimada nesta condição quando comparada com o armazenamento sob temperatura de $25^{\circ} \mathrm{C}$ e com o mesmo teor de água inicial (Figura 5B).

Os menores percentuais de perda de matéria seca foram apresentados pelos grãos armazenados com teor de água de $14,8 \%$ e os maiores percentuais para os grãos armazenados com teor de água de 17,9\% (Figura 5).

Trabalhos realizados por Saul e Steele (1966) demonstraram que para sistemas abertos, a taxa de perda de matéria seca aumenta à medida em que se aumenta o tempo de armazenamento, a temperatura e o teor de água dos grãos.

Diferentemente, o que se verificou para o sistema de armazenamento em bolsas herméticas é que a taxa de perda de matéria seca decresce ao longo do tempo até atingir valores desprezíveis e o incremento na perda de matéria seca passa então a ser também, desprezível.

Saul e Steele (1966) reportaram ainda, que grãos de milho armazenados em sistemas abertos têm seu padrão de qualidade comprometido quando atingem níveis de perda de matéria seca de aproximadamente $0,5 \%$. A partir destes trabalhos, muitos pesquisadores passaram a utilizar o valor de $0,5 \%$ como o máximo permissível de perda de matéria seca em modelos de simulações para secagem e armazenamento de milho. NG et al. (1998), no entanto, verificaram que o máximo permitido de perda de matéria seca para os grãos de milho colhidos mecanicamente ( 25 a $35 \%$ de danos mecânicos) deve ser de $0,35 \%$ para que não tenham seu padrão de qualidade reduzido. Gupta $e t$ al. (1998) também verificaram que quando o milho tem uma perda de matéria seca de $0,5 \%$, sua qualidade já pode ser

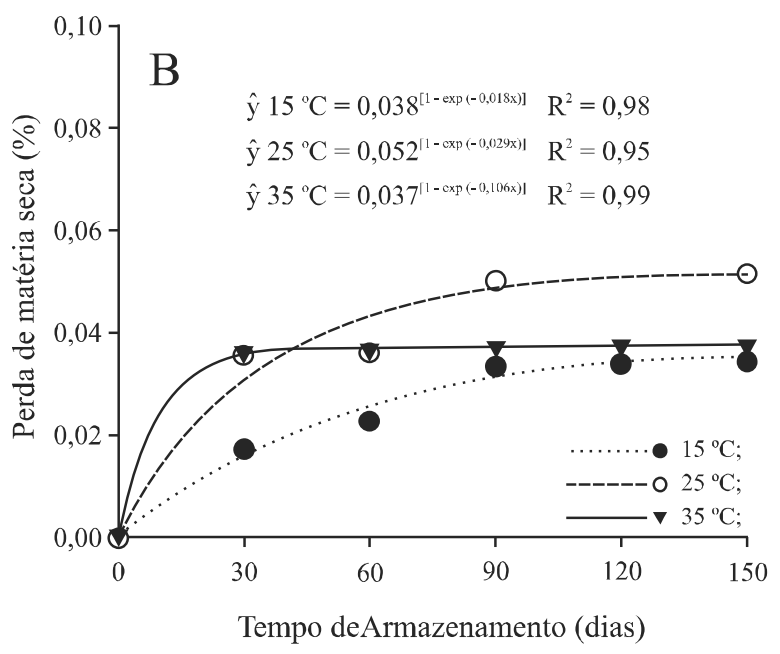

considerada inaceitável sob determinadas condições de temperatura e teor de água.

A perda do potencial de germinação dos grãos de milho após 30 dias de armazenamento em bolsas herméticas para determinadas condições (teor de água de 14,8\% em $35{ }^{\circ} \mathrm{C}$ e teor de água de $17,9 \%$ em 25 e $35^{\circ} \mathrm{C}$ ) (Figura 2) pode ocasionar redução de seu valor como semente. Com base nestes resultados, a perda de matéria seca admissível para o armazenamento em bolsas herméticas é de $0,015 \%$, bastante inferior aos valores admissíveis para sistemas abertos.

A partir dos laudos de classificação emitidos pelo Instituto Mineiro de Agropecuária - IMA, verificou-se que apenas o milho armazenado com teor de água de 17,9\% em temperatura de $35^{\circ} \mathrm{C}$ e aos 150 dias foi classificado como Tipo 2, sendo que esta classificação se deu principalmente devido ao aumento do percentual de grãos ardidos e avariados. Em todas as demais condições e períodos o produto foi classificado como Tipo 1 .

Considerando apenas a classificação comercial como padrão de qualidade, a perda de matéria seca admissível para o armazenamento em bolsas herméticas seria de $0,037 \%$.

\section{CONCLUSÕES}

1.Em 150 dias de armazenamento em bolsas herméticas, a perda de matéria seca para os grãos de milho com teor de água de 17,9\% é aproximadamente 4 vezes superior à verificada para o produto armazenado com teor de água de $14,8 \%$; 
2.Com base nos resultados de percentual de germinação e massa específica aparente da matéria seca, o limite de $0,015 \%$ de perda de matéria seca pode ser considerado como máximo admissível para a manutenção da integridade dos grãos durante o armazenamento em bolsas herméticas;

3. Aos 150 dias, apenas, os grãos de milho armazenados com teor de água de $17,9 \%$ em temperatura de $35{ }^{\circ} \mathrm{C}$ apresentam classificação inferior (Tipo 2) à do início do experimento e esta condição coincide com a perda de matéria seca de $0,037 \%$.

\section{AGRADECIMENTOS}

Os autores agradecem à CAPES e a UFV pela concessão de recursos do projeto de pesquisa, bolsa de estudo, logística e infraestrutura.

\section{REFERÊNCIAS}

ADHIKARINAYAKE, B. T.; PALIPANE, K. B.; MULLER, J. Quality change and mass loss of paddy during airtight storage in a ferro-cement bin in Sri Lanka. Journal Stored Product research, v. 42, n. 03, p. 377-390, 2006.

AGUIAR, R. W. S. et al. Controle de pragas em grãos armazenados utilizando atmosfera modificada. Bioscience Journal, v. 20, n. 01, p. 21-27, 2004.

ALVES, W. M. et al. Taxa respiratória e perda de matéria seca no armazenamento de milho sob diferentes temperaturas. Revista Brasileira de Armazenamento, v. 31, n. 01, p. 59-64, 2006.

BERN, C. J.; STEELE, J. L.; MOREY R. V. Shelled corn $\mathrm{CO}_{2}$ evolution and storage time for $0.5 \%$ dry matter loss. Applied Engineering in Agriculture, v. 18, n. 06, p. 703-706, 2002.

BRASIL. Mistério da Agricultura, Pecuária e Abastecimento. Portaria $n^{\circ} 845$ de 08.11.1976. Especificações para padronização, classificação e comercialização interna do milho. 4 1976. Disponível em: <http://www.claspar.pr.gov.br/arquivos/ File/pdf/milho 845 _76.pdf>. Acesso em: 20 nov. 2011.

BRASIL. Ministério da Agricultura e Reforma Agrária. Regras para análise de sementes. Brasília: Mapa/ACS, 2009. 399 p.

COSTA, A. R. et al. Qualidade de grãos de milho armazenados em silos bolsa. Revista Ciência Agronômica, v. 41, n. 02, p. 200-207, 2010.

DILLAHUNTY, A. L. et al. Effect of moisture content and temperature on respiration rate of rice. Cereal Chemistry, v. 77, n. 05 , p. $541-543,2000$.

EMEKCI, M. et al. Respiration of Tribolium castaneum (Herbst) at reduced oxygen concentrations. Journal of Stored Products Research, v. 38, n. 05, p. 413-425, 2002.
EMEKCI, M. et al. Respiration of Rhyzopertha dominica (F.) at reduced oxygen concentrations, Journal of Stored Products Research, v. 40, n. 01, p. 27-38, 2004.

FARONI, L. R. A. et al. Armazenamento de soja em silos tipo bolsa. Engenharia Agrícola, v. 29, n. 01, p. 91-100, 2009.

GASTÓN, A. et al. Mathematical modelling of heat and moisture transfer of wheat stored in plastic bags (silobags). Biosystems Engineering, v. 104, n. 01, p. 72-85, 2009.

GUPTA, P. et al. Effect of dry matter loss on corn quality. Applied Engineering in Agriculture, v. 15, n. 05, p. 501-507, 1999.

ILELEJI, K.E.;WILCKE, W.F.; MOREY, R. V. Relative storability of high-oil and BT corn hybrids compared to conventional hybrids. Transactions of the ASABE, v. 46, n. 02, p. 407-414, 2003.

MORENO, M. E.; BENAVIDES, C.; RAMIREZ, J. The influence of hermetic storage on the behavior of maize seed germination. Seed Science and Technology, v. 16, n. 02, p. 427-434, 1988.

NAVARRO, S.; DONAHAYE, E. J. Innovative environmentally friendly technologies to maintain quality of durable agricultural products. In: BEN YEHOSHUA, S. (Ed.), Environmentally Friendly Technologies for Agricultural Produce Quality. Boca Raton, Flórida: CRC Press, 2005. p. 204-260.

NG, H. F. et al. Mechanical damage and corn storability. Transaction of the ASAE, v. 41, n. 04, p. 1095-1100, 1998.

QUEZADA, M. Y. et al. Hermetic storage system preventing the proliferation of Prostephanus truncatus Horn and storage fungi in maize with different moisture contents. Postharvest Biology and Technology, v. 39, n. 03, p. 321-326, 2006.

RUPOLLO, G. et al. Sistemas de armazenamentos hermético e convencional na conservabilidade de grãos de aveia. Ciência Rural, v. 34, n. 06, p. 1715-1722, 2004.

SANTOS, S. B. et al. Quality of maize grains treated with allyl isothiocyanate stored in hermetic bags. Journal of Stored Products Research, v. 46, n. 02, p. 111-117, 2010.

SAUL, R. A.; STEELE, J. L. Why damaged shelled corn cost more to dry. Agricultural Engineering, v. 47, n. 06, p. 326, 1966.

SHUNMUGAM, G. et al. Diffusion of carbon dioxide through grain bulks. Journal Stored Products Research, v. 41, n. 02, p. 131-144, 2005.

VILLERS, P.; BRUIN, T.; NAVARRO, S. Safe storage of grain in the tropics: A comparison of hermetic storage in flexible silos versus rigid metal or concrete silos. In: WEST, A.; BROWN, J. Feed Technology Update. Honolulu: Linx Publishing, 2006. p. 17-22.

VOGEL, A. I. Análise química quantitativa. 6. ed. Rio de Janeiro: LTC-, 2002. 462 p.

WHEINBERG, Z. G. et al. The effect of moisture level on high-moisture maize (Zea mays L.) under hermetic storage conditions - in vitro studies. Journal Stored Products Research, v. 44, n. 02, p. 136-144, 2008. 